\title{
Ligation of the middle hepatic vein to increase hypertrophy induction during the ALPPS procedure
}

\author{
F. Dondorf ${ }^{1}$ (1) - A. Ali Deeb ${ }^{1} \cdot$ A. Bauschke ${ }^{1} \cdot$ P. Felgendreff ${ }^{1,2} \cdot$ H. M. Tautenhahn ${ }^{1,2} \cdot$ M. $^{\text {Ardelt }}{ }^{1} \cdot$ U. Settmacher ${ }^{1}$. $^{2}$ \\ F. Rauchfuss ${ }^{1}$
}

Received: 2 January 2021 / Accepted: 26 April 2021 / Published online: 10 May 2021

(C) The Author(s) 2021

\begin{abstract}
Purpose Here, we analyse the technical modification of the ALPPS procedure, ligating the middle hepatic vein during the first step of the operation to enhance remnant liver hypertrophy.

Methods In 20 of 37 ALPPS procedures, the middle hepatic vein was ligated during the first step. Hypertrophy of the functional remnant liver volume was assessed in addition to postoperative courses.

Results Volumetric analysis showed a significant volume increase, especially for patients with colorectal metastases. Pre-existing liver parenchyma damage (odds ratio $=0.717, p=0.017$ ) and preoperative chemotherapy were found to be significant predictors (odds ratio $=0.803, p=0.045$ ) of higher morbidity and mortality. In addition, a survival benefit for maintenance of middle hepatic vein was shown.

Conclusion This technical modification of the ALPPS procedure can accentuate future liver remnant volume hypertrophy. The higher morbidity and mortality observed are most likely associated with pre-existing parenchymal damage within this group.
\end{abstract}

Keywords ALPPS $\cdot$ Middle hepatic vein $\cdot$ Hypertrophy induction

\section{Introduction}

The only chance for long-term tumour-free survival in patients with primary or secondary liver tumours is R0 resection [1]. In advanced tumours, the quality and quantity of the future liver remnant (FLRV) is the landmark for resectability. If the residual liver volume is insufficient, patients can develop smallfor-size syndrome (SFSS), which has a high risk of mortality $[2,3]$. For "normal" parenchyma, an FLRV of $\geq 25 \%$ should be left. A higher FLRV (35-40\%) is recommended if chronic liver parenchyma damage is present (e.g., due to chemotherapy-associated liver damage, liver fibrosis or cirrhosis) [4-7].

F. Dondorf and A. Ali Deeb contributed equally to this work.

F. Dondorf

Felix.Dondorf@med.uni-jena.de

1 Department of General, Visceral and Vascular Surgery, Jena University Hospital, Am Klinikum 1, 07747 Jena, Germany

2 Research Program "Else Kröner-Forschungskolleg AntiAge", Jena University Hospital, Jena, Germany
The ALPPS procedure was developed to increase remnant liver volume, in addition to several preoperative interventions. The advantage is rapid hypertrophy of the remaining liver, but morbidity and mortality rates are high [8]. For example, based on collected data from the international ALPPS Registry, Schadde et al. described a morbidity rate of $28 \%$ (ClavienDindo $\geq \mathrm{IIIb}$ ) and a mortality rate of $9 \%$. Subgroup analysis revealed a worse prognosis for older patients ( $>60$ years) and those with non-colorectal liver tumours [9]. The main cause of early postoperative mortality is liver insufficiency due to SFSS. To lower invasivity and to increase hypertrophy, for which the complete mechanism is not fully understood, several modifications of the ALPPS procedure have already been investigated and published. Along with the partial split and laparoscopic approaches, other modifications have been published, including radiofrequency-assisted liver partition with portal vein ligation (RALPP), laparoscopic microwave ablation and portal vein ligation for staged hepatectomy (LAPS), associating liver tourniquet and portal ligation for stage hepatectomy (ALTPS), and sequential ALTPS [10-12].

Based on known conditioning procedures, including portal vein embolization + hepatic vein deprivation [13-15] and experimental work by Schadde et al. that analysed hepatic 
Table 1 Main characteristics of the two groups: data shown the mean \pm standard deviation. Abbreviations: metastases of colorectal carcinoma (CRC), hepatocellular carcinoma (HCC), intrahepatic cholangiocellular carcinoma (CCC). Other: 1 case of adrenal carcinoma metastasis and 1 case of renal cell carcinoma metastasis

\begin{tabular}{llll}
\hline & & $\begin{array}{l}\text { MHV preserved } \\
n=17\end{array}$ & $\begin{array}{l}\text { MHV ligated } \\
n=20\end{array}$ \\
\hline Sex & Male & 8 & 9 \\
\multirow{2}{*}{ Entity } & Female & 9 & 11 \\
& CRC & 10 & 10 \\
& HCC & 3 & 4 \\
& CCC & 3 & 5 \\
Age $($ a) & Other & 1 & 1 \\
BMI $\left(\mathrm{kg} / \mathrm{m}^{2}\right)$ & Mean & $63.5 \pm 10$ & $64.4 \pm 11.1$ \\
\hline
\end{tabular}

conditioning without transection [16], we compared "classical" ALPPS with ALPPS plus middle hepatic vein ligation. In our opinion, simultaneous ligation of the middle hepatic vein (MHV) and the right portal vein during the first step of the ALPPS procedure should be accompanied by a further increase in FLRV hypertrophy.

This work summarises our experience with ligation of the MHV during the first step of the ALPPS procedure in view of the hypertrophic increase in the FLRV.

\section{Methods}

Between June 2014 and June 2019, 37 ALPPS procedures with complete parenchyma transection were performed at our centre, similar to the original description of the ALPPS procedure. In 20 of the 37 patients, ligation of the middle hepatic vein (MHV) was performed during the first step. There was no randomisation of the patients, and the choice of the selected operative approach depended on the preference of the surgeon.

The mean age was $64 \pm 10.5$ years, and the median age of the patients who underwent surgery was 65 years (range 34
78). The indications for surgery and the basic data of the patients are listed in Tables 1, 2 and 3.

In addition to laboratory chemistry, the LiMAx test (Humedics, Berlin, Germany) was performed prior to step 1 and prior to step 2 (Table 4). All patients were examined by contrast-enhanced CT scans preoperatively, postoperatively immediately after the 1 st step, and 1 day before the 2nd step.

Subsequently, three-dimensional volumetric analyses were performed with the program Synapse 3D (FUJIFILM, Tokyo, Japan). This software offers the possibility of measuring different liver volumes and calculating tumour volumes.

For volumetric analysis, contrast-enhanced $\mathrm{CT}$ is required to which the software can refer. The optimal slice thickness is $0.63 \mathrm{~mm}$.

By extracting the liver in several individual slices ( 3 axes: axial, sagittal and coronary), the software can generate a threedimensional reconstruction with (automatic) measurement of total liver volumes. In addition to the future liver remnant volume (FLRV), the total functional liver volume was determined. This was generated by subtracting tumour volumes, tumour volumes $<50 \mathrm{ml}$ were not analysed.

Pre-existing liver parenchyma damage was not detected based on laboratory data, only histologically proven fibrosis of any degree or cirrhosis in the tumour-free liver parenchyma was analysed [17, 18].

As there was no severe steatosis hepatis ( $>66 \%$ of liver parenchyma) in our patient population, steatosis was not considered as parenchyma damage in this analysis.

In this work, the definition of postoperative liver failure in the sense of an SFSS was generated from a combination of different common definitions [3, 19]. The following parameters were combined to assess functional impairment after the second ALPPS step:

a. Persistent hyperbilirubinemia with a peak of $>120 \mu \mathrm{mol} / \mathrm{l}$ from the 5th postoperative day. Any biliary complications were excluded AND

b. Deviation from normal coagulation status (quick < 65\%) despite supportive therapy (vitamin K substitution)
Table 2 Main characteristics of the tumour entities. Abbreviations: chemotherapy $(\mathrm{Cx})$, metastases of colorectal carcinoma (CRC), hepatocellular carcinoma (HCC), intrahepatic cholangiocellular carcinoma (CCC). Other: 1 case of adrenal carcinoma metastasis and 1 case of renal cell carcinoma metastasis

\begin{tabular}{|c|c|c|c|c|c|}
\hline & $\begin{array}{l}\text { Total } \\
n\end{array}$ & $\begin{array}{l}\text { Previous surgery } \\
n(\%)\end{array}$ & $\begin{array}{l}\text { Previous Cx } \\
n(\%)\end{array}$ & $\begin{array}{l}\text { Period Cx } \\
\text { month }\end{array}$ & $\begin{array}{l}\text { Time interval } \mathrm{Cx} / \text { surgery } \\
\text { days }\end{array}$ \\
\hline $\mathrm{HCC}$ & 6 & 0 & 0 & / & I \\
\hline $\mathrm{CCC}$ & 9 & 0 & $2(22.2)$ & $4.5 \pm 0.5$ & 1 \\
\hline CRC & 20 & $20(100)$ & $13(65)$ & $3.34 \pm 0.94$ & $106.5 \pm 83.04$ \\
\hline Other & 2 & $1(50)$ & $1(50)$ & 2 & 34 \\
\hline
\end{tabular}


Table 3 Main characteristics of the two groups. Abbreviation: chemotherapy $(\mathrm{Cx})$

\begin{tabular}{llllll}
\hline & $\begin{array}{l}\text { Total } \\
n\end{array}$ & $\begin{array}{l}\text { Previous surgery } \\
n(\%)\end{array}$ & $\begin{array}{l}\text { Previous Cx } \\
n(\%)\end{array}$ & $\begin{array}{l}\text { Period Cx } \\
\text { month }\end{array}$ & $\begin{array}{l}\text { Time interval Cx/surgery } \\
\text { days }\end{array}$ \\
\hline MHV preserved & 17 & $11(64.7)$ & $8(47.1)$ & $3.34 \pm 0.94$ & $\begin{array}{l}102.8 \pm 90.52 \\
77.4 \pm 50.83\end{array}$ \\
MHV ligated & 20 & $10(50)$ & $8(40)$ & $5.33 \pm 3.2$ & 7.450 \\
\hline
\end{tabular}

Table 4 Main results of LiMAx test divided by group - MHV preserved, MHV ligated and divided due to tumour entities. Abbreviation: small-for-size syndrome (SFSS)

Table 5 Main results of volumetries, divided in both groups-MHV preserved, MHV ligated. Abbreviations: functional total liver volume (func. TLV), total body weight (TBW)

\begin{tabular}{lllll}
\hline & $\begin{array}{l}\text { Total } \\
n\end{array}$ & $\begin{array}{l}\text { LiMAx prior to step } 1 \\
\mu \mathrm{g} / \mathrm{h} / \mathrm{kg}\end{array}$ & $\begin{array}{l}\text { LiMAx prior to step 2 } \\
\mu \mathrm{g} / \mathrm{h} / \mathrm{kg}\end{array}$ & $\begin{array}{l}\text { SFSS } \\
n(\%)\end{array}$ \\
\hline MHV preserved & 17 & $488.77 \pm 113.7$ & $430.36 \pm 126.33$ & $1(5.88)$ \\
MHV ligated & 20 & $475.27 \pm 152.74$ & $437.5 \pm 141.43$ & $6(30)$ \\
HCC & 6 & $412 \pm 85.94$ & $343.5 \pm 83.70$ & $2(33.3)$ \\
CCC & 9 & $513.63 \pm 182.14$ & $449.33 \pm 175.15$ & $1(11.1)$ \\
CRC & 20 & $483.8 \pm 90.7$ & $459.34 \pm 120.63$ & $4(20)$ \\
other & 2 & $/$ & $/$ & 0 \\
\hline
\end{tabular}

\begin{tabular}{lll}
\hline & MHV preserved & MHV ligated \\
\hline FLRV-Increase (ml) & $218(134-333)$ & $221(70-428)$ \\
Percentage of FLRV-Increase (\%) & $49.9 \%(19.8-74.3 \%)$ & $54.9 \%(16.7-96.1 \%)$ \\
FLRV-Increase/func. TLV (\%) & $5.54 \%(1.5-15.4 \%)$ & $6 \%(-1.4-15.4 \%)$ \\
FLRV-Increase/TBW (\%) & $0.29 \%(0.18-0.46 \%)$ & $0.3 \%(0.12-0.64 \%)$ \\
\hline
\end{tabular}

Retrospective collection of basic data was carried out using the program Microsoft Excel Office (Microsoft Cooperation, Redmond, WA, USA). Statistical processing of patient data was performed using the IBM SPSS Statistics 25 (IBM, Armonk, NY, USA) statistical program.

Significance for two independent samples was assessed using the Mann-Whitney $U$-test and we used the KolmogorovSmirnov test to check for a normal distribution. The Wilcoxon test was used to observe differences between two paired samples and the z-standardised test was applied to test for significance. The bilateral significance level was $0.05 \pm 1.96$.

\section{Results}

The median increase in FLRV volume in the whole group was $54.1 \%$ (range $16.7-96.1 \%$ ), with a median time interval of 9 days. Subdividing the cohort by the handling of the middle liver vein, an advantage of the MHV ligation group (54.9\%, range $16.7-96.1 \%$, in 8.5 days) compared to the conventional ALPPS procedure (49.9\%, range $19.8-74.3 \%$, in 10 days) was evident, but not statistically significant $(p=0.082)$. If only the subgroup of patients with colorectal liver metastases
Fig. 1 Comparison of the increase in FLR in relation to the two groups: MHV preserved and MHV ligated. Left: Comparison of the ratio (FLRV2/FLRV1) in $\%$. Right: Comparison of the ratio (FLR/total functional liver volume) in $\%$. The total functional liver volume was generated by subtracting the tumour volumes, and tumour volumes $<50 \mathrm{ml}$ were not scored

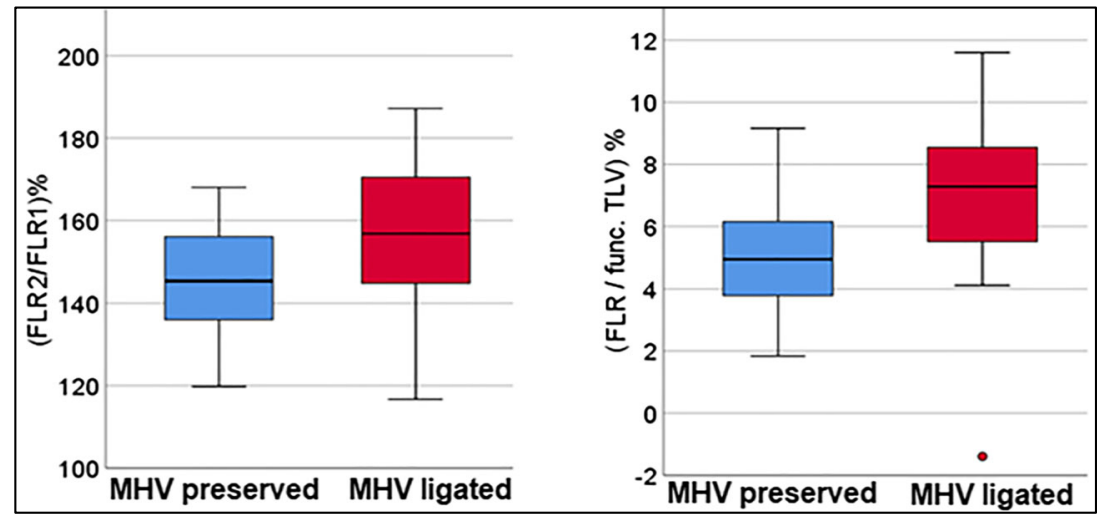




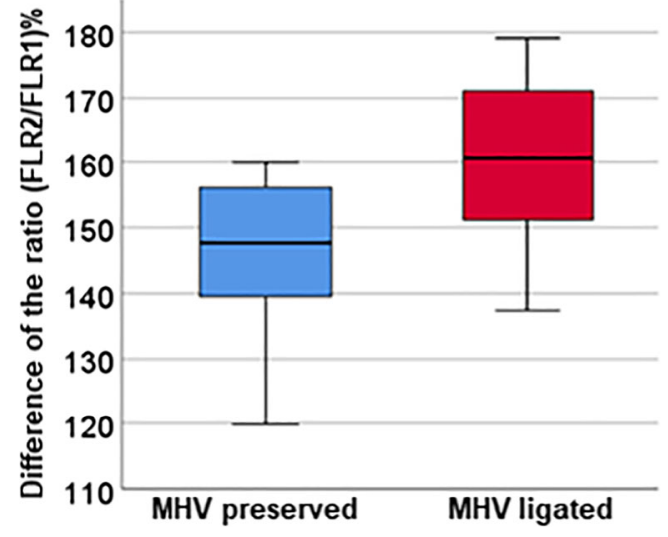

Fig. 2 Representation of the ratio (FLRV2/FLRV1) in \% in subgroup analysis of CRC patients ( $p=0.028)$

was considered, the FLRV2/FLRV1 ratio was statistically significant in favour of MHV ligation $(p=0.028)$ (Table 5, Figs. 1 and 2).

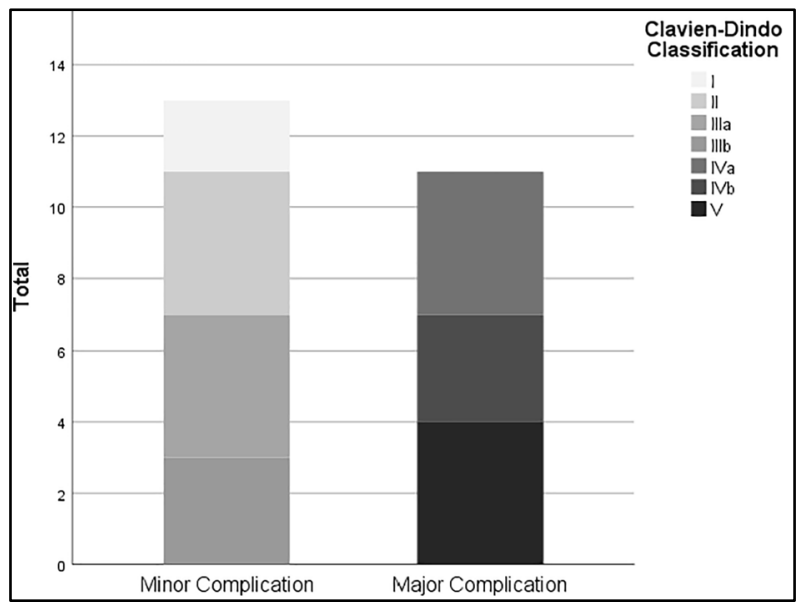

Major complications (Clavien-Dindo > IIIb) occurred in 11 patients $(29.7 \%)$. Eight patients developed major hepatic complications, of which small for size syndrome was the most common, in 7 patients. One patient experienced prolonged biliary leakage. The remaining three patients had major nonhepatic complications (two pulmonary artery embolisms and one media infarction) (Figs. 3 and 4). Small for size syndrome was the unique cause of 90-day mortality $(n=4 ; 10.8 \%)$ (Table 6).

As risk factors for postoperative complications and mortality, two major factors were analysed in our cohort. In addition to pre-existing liver parenchyma changes ( $p=0.017$, postoperatively histologically proven fibrosis or cirrhosis), preoperative chemotherapy $(p=0.045)$ was a significant predictor, especially for the development of SFSS.

According to liver parenchyma damage, eight patients in our cohort had mild fibrosis (F1) and three patients had cirrhosis (F4). The remaining 26 patients exhibited no relevant

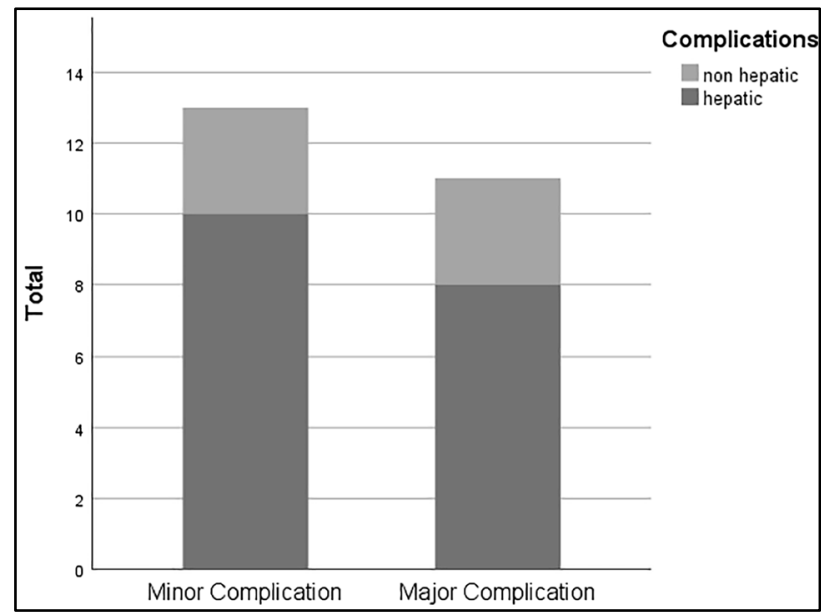

Fig. 3 Division of complications into minor and major complications: on the left as division by Clavien-Dindo; on the right by hepatic and non-hepatic complications
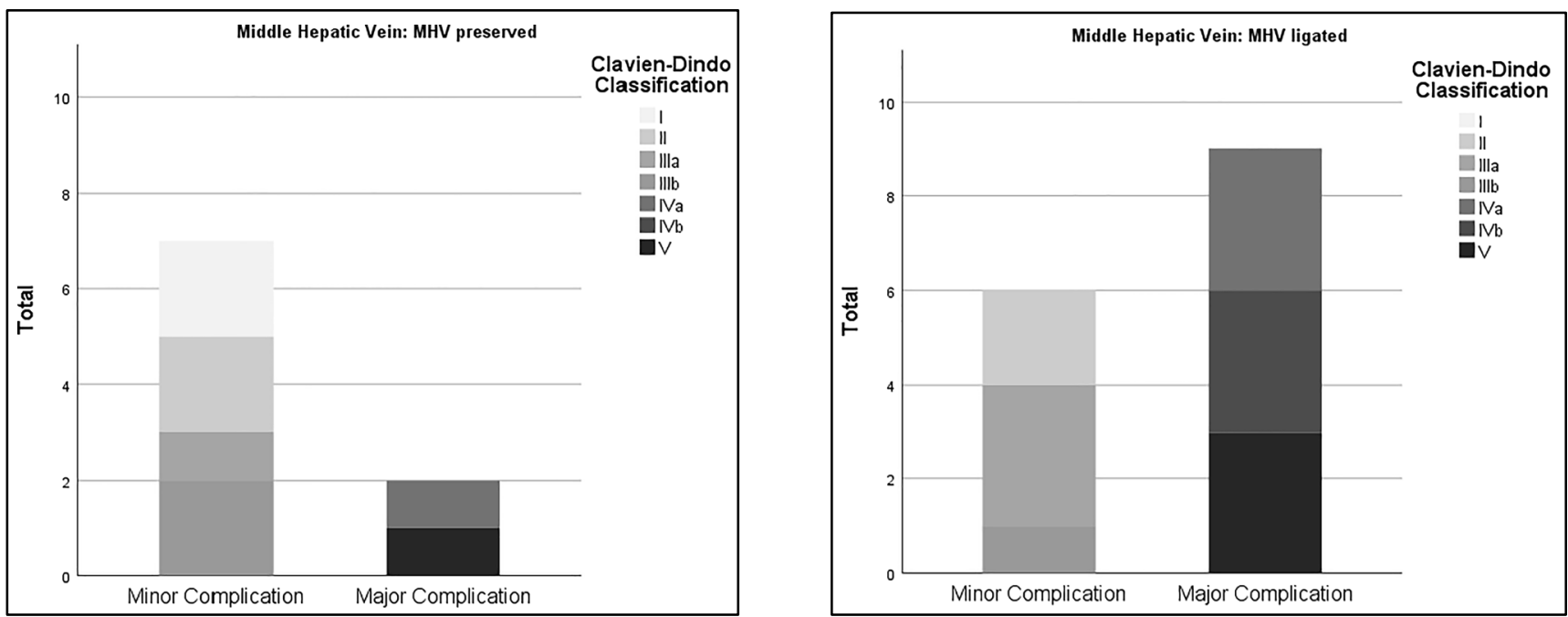

Fig. 4 Division of complications into minor and major complications: on the left MHV preserved; on the right MHV ligated 
Table 6 Presentation of morbidity and mortality after MHV preservation/ligation

\begin{tabular}{llll}
\hline & $\begin{array}{l}\text { Total } \\
n=37(\%)\end{array}$ & $\begin{array}{l}\text { MHV preserved } \\
n=17(\%)\end{array}$ & $\begin{array}{l}\text { MHV ligated } \\
n=20(\%)\end{array}$ \\
\hline Morbidity (total) & $24(64.9)$ & $9(52.9)$ & $15(75)$ \\
Major complication & $11(29.7)$ & $2(11.8)$ & $9(45)$ \\
hepatic complication & $18(48.6)$ & $6(35.3)$ & $12(60)$ \\
SFSS & $7(18.9)$ & $1(5.9)$ & $6(30)$ \\
90-day mortality & $4(10.8)$ & $1(5.9)$ & $3(15)$ \\
\hline
\end{tabular}

parenchymal changes. Regarding chemotherapy, $59.46 \%$ of the patients in our cohort were not treated with preoperative chemotherapy; $24.32 \%$ were given folinic acid-based chemotherapy, and the remaining $16.22 \%$ had an individual chemotherapy plan.

Subgroup analysis of the data showed higher morbidity in the MHV ligation group. Overall survival in our cohort was a median survival time of 32 months, and the mean survival time was 31 months (Fig. 5, Tables 7 and 8). Four patients were excluded from the evaluation due to a lack of follow-up information.

\section{Discussion}

Based on the history and development of the ALPSS procedure, in the very first patient in whom this procedure was performed intraoperatively (emergency) and without prior planning, the middle hepatic vein was divided during the first step [20]. Considering the progression of its development, it must be noted that in the initial description of the procedure, the middle vein was preserved during the first step and was divided during the second step [8]. Thus, routine transection of the middle hepatic vein is not in accordance with the protocol of the initial ALPPS description.

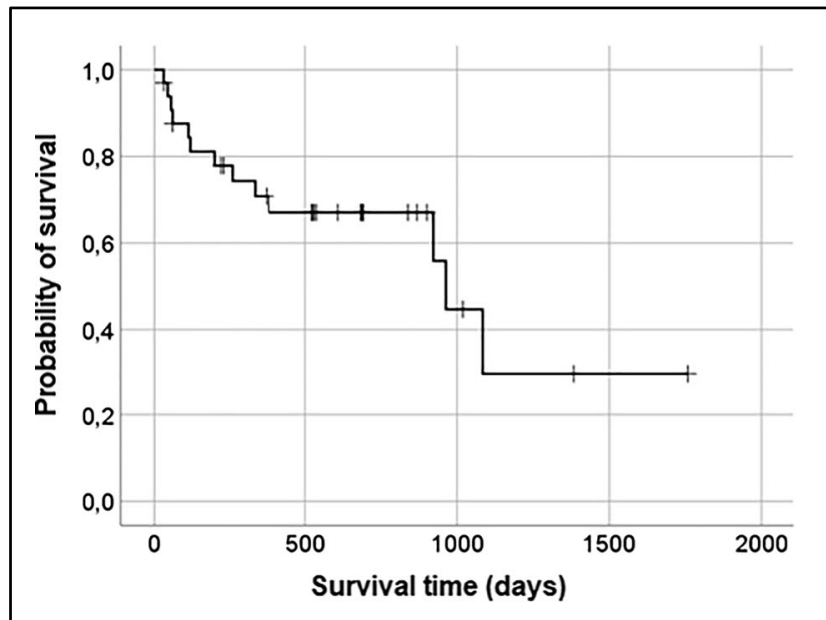

Table 7 Overall survival (OS) and disease-free survival (DFS) divided by MHV preservation/ligation

\begin{tabular}{lllll}
\hline & & $\begin{array}{l}\text { Total } \\
\%\end{array}$ & $\begin{array}{l}\text { MHV preserved } \\
\%\end{array}$ & $\begin{array}{l}\text { MHV ligated } \\
\%\end{array}$ \\
\hline OS & 1 year & 73.1 & 90 & 62.5 \\
& 2 years & 56.3 & 50 & 58.3 \\
\multirow{2}{*}{ DFS } & 1 year & 50 & 60 & 42.9 \\
& 2 years & 14.3 & 0 & 29 \\
\hline
\end{tabular}

In our opinion, this is the first time that the effect of ligating the MHV in step 1 of the ALPPS procedure has been described in a patient series.

We assumed that in addition to portal vein ligation and complete transection of the parenchyma in step 1, MHV ligation should have an additive effect on hypertrophy induction in the residual liver. The approach of combined interventional venous and portal venous embolization is currently being investigated [21] and appears to support our hypothesis, though the combination of ALPPS and venous occlusion has not yet been described in this way.

In this study, we were only able to identify this effect as statistically significant for CRC-MTS patients in our cohort. Technically, central ligation of the MHV is only required for oncosurgical reasons in patients with tumour load in segment IVa.

In the original description of the procedure, the maintenance of the MHV in step 1 is propagated [8]. Shortly afterwards, the procedure was modified with ligation of the MHV [22]. Performing this interventionally to induce hypertrophy has already been suggested, but for the right liver vein [23]. There are two different current recommendations: supporters of principle ligation [24] and those who in principle receive the MHV in step 1 [25]. However, there is no comparison to date.

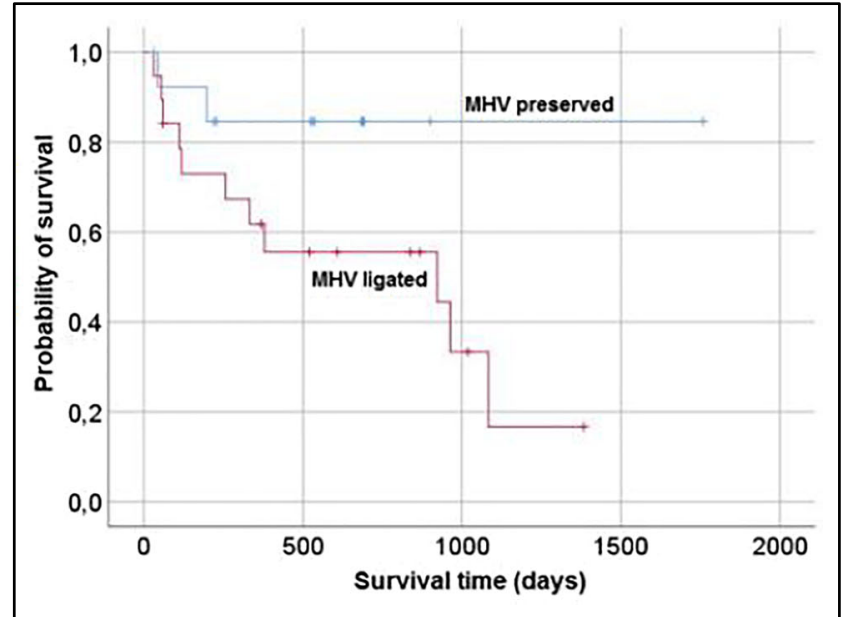

Fig. 5 Kaplan-Meier curves showing cumulative overall survival. Left: Overall collective, right: overall collective differentiation by MHV preservation and MHV ligation 
Table 8 Hospital stay, adjuvant therapy, OS, DFS and in-house mortality divided by MHV preservation/ligation

\begin{tabular}{lllllll}
\hline & $\begin{array}{l}\text { Total } \\
n\end{array}$ & $\begin{array}{l}\text { Hospital stay } \\
\text { days }\end{array}$ & $\begin{array}{l}\text { Adjuvant therapy } \\
n(\%)\end{array}$ & $\begin{array}{l}\text { OS } \\
\text { days }\end{array}$ & $\begin{array}{l}\text { DFS } \\
\text { days }\end{array}$ & $\begin{array}{l}\text { In house mortality } \\
n(\%)\end{array}$ \\
\hline MHV preserved & 17 & $35.76 \pm 9.66$ & $6(35.3)$ & $551.43 \pm 424.43$ & $325.64 \pm 226.56$ \\
MHV ligated & 20 & $45.6 \pm 27.43$ & $6(30)$ & $525.21 \pm 413.77$ & $312.44 \pm 342.00$ & $3(15)$ \\
\hline
\end{tabular}

The processing of our data revealed completion with the second step after an average of 9 days, though it must be noted that an average of 9-14 days is reported in the literature [26]. Our cohort showed an average time advantage for the MHV ligation group of 8.5 days. This can be explained by faster hypertrophy, even though randomisation was not performed for this study because of the retrospective design.

Hepatic vein embolization induces liver hypertrophy through an increase in portal pressure by regurgitation into the portal vein through the sinusoids [27]. In contrast, the pathophysiology of hypertrophy in ALPPS is still not fully understood, yet similar mechanisms must be present [28]. The combination of both mechanisms was addressed in this technical modification. Additional hypertrophy of the FLRV was shown, albeit not significant in the overall cohort but rather in relation to those with colorectal liver metastases.

Considering that patients with colorectal cancer can benefit from an ALPPS procedure and that the modification with respect to hypertrophy was significant in this patient group, it is obvious that patient selection is of enormous importance, which has already been demonstrated by other research groups [29-31]. In this report, it became also apparent that CRC-MTS patients especially benefit from the ALPPS procedure. In addition to selection of the tumour entity, the liver parenchyma and any pretreatment play a relevant role $[25$, 32].

Overall, technical modification with ligation of the middle hepatic vein has a positive effect on these patients and can accentuate hypertrophy.

Our analysis showed that pretreatment with chemotherapy and liver parenchyma damage significantly reduce hypertrophy. Nevertheless, further studies are needed, particularly regarding liver regeneration within the setting of ALPPS after chemotherapy [33, 34].

In general, not every patient can be treated by the ALPPS procedure, and further work, including preoperative functional analysis, is necessary [25].

The higher morbidity and mortality of the MHV group can be explained by the retrospective data analysis as a limitation, as the selection of patients was "intuitive" and not randomised intraoperatively; indeed, to achieve a more substantial increase in hypertrophy, patients with a worse parenchymal condition comprised the ligation group. Ultimately, the population reported herein reflects the indication common in the literature. Because the data were collected from 2014 to 2019 , it is also possible to observed a change in patient selection towards colorectal metastasis, which was also found by Chan et al. [26].

The patient population presented here had a major complication rate $(\mathrm{CD}>3 \mathrm{~b})$ of $29.7 \%$. The SFSS rate was $18.9 \%$, and the 90 -day mortality rate was $10.8 \%$. Considering this within the context of the literature, several papers show similar results. For example, Vicente et al. found an SFSS rate of 22.2\% [35], and Zhang et al. indicated that $75 \%$ of ALPPS-associated mortality was due to post hepatectomy liver failure [36]. In addition, a recent review by Chan et al. from 2020 highlights that the main complications of ALPPS are high morbidity (ClavienDindo $\geq$ Grade IIIB complications) and 90-day mortality. Morbidity rates range from $14-50 \%$; however, the incidence of all postoperative complications has been reported to range from 53-90\%, with 90-day mortality rates of 0-28.7\% [26].

Nevertheless, it must be clearly stated that the decision to ligate MHV was an intraoperative decision by the surgeon and must therefore be mentioned in addition to the lack of randomisation as a limitation. In our opinion, this can be regarded as a technical error in the work and should therefore be further evaluated randomly in additional work; this must be evaluated as a clear selection bias of the study.

\section{Conclusion}

In summary, this technical modification involving ligation of the median hepatic vein during the first step of the ALPPS procedure has a positive influence on the increase in FLRV, but without significance in our series. Further work on ALPPS, subsequent liver regeneration and patient selection is absolutely necessary to minimise the high mortality and morbidity rates and to promote patient safety.

Authors' contributions Dondorf F. and Ali Deeb A. participated in study conception and design, acquisition of data, analysis and interpretation of data and drafting of the manuscript. Bauschke A., Felgendreff P., Tautenhahn HM. and Ardelt M. participated in acquisition of data, drafting of the manuscript and critical revision of the manuscript. Settmacher U. and Rauchfuss F. participated in study conception and design, acquisition of data, analysis and interpretation of data, drafting of manuscript and critical revision of the manuscript. 
Funding Open Access funding enabled and organized by Projekt DEAL.

\section{Declarations}

Ethics approval All procedures performed in studies involving human participants were in accordance with the ethical standards of the institutional and/or national research committee and with the 1964 Helsinki Declaration and its later amendments or comparable ethical standards.

Conflict of interest The authors declare no competing interests.

Open Access This article is licensed under a Creative Commons Attribution 4.0 International License, which permits use, sharing, adaptation, distribution and reproduction in any medium or format, as long as you give appropriate credit to the original author(s) and the source, provide a link to the Creative Commons licence, and indicate if changes were made. The images or other third party material in this article are included in the article's Creative Commons licence, unless indicated otherwise in a credit line to the material. If material is not included in the article's Creative Commons licence and your intended use is not permitted by statutory regulation or exceeds the permitted use, you will need to obtain permission directly from the copyright holder. To view a copy of this licence, visit http://creativecommons.org/licenses/by/4.0/.

\section{References}

1. Tarasik A, Jaroszewicz J, Januszkiewicz M (2017) Surgical treatment of liver tumors - own experience and literature review. Clin Exp Hepatol 3(1):1-8. https://doi.org/10.5114/ceh.2017.65498

2. van den Broek MA, Olde Damink SW, Dejong CH, Lang H, Malago M, Jalan R, Saner FH (2008) Liver failure after partial hepatic resection: definition, pathophysiology, risk factors and treatment. Liver Int 28(6):767-780. https://doi.org/10.1111/j. 1478-3231.2008.01777.x

3. Rahbari NN, Garden OJ, Padbury R, Brooke-Smith M, Crawford M, Adam R, Koch M, Makuuchi M, Dematteo RP, Christophi C, Banting S, Usatoff V, Nagino M, Maddern G, Hugh TJ, Vauthey JN, Greig P, Rees M, Yokoyama Y, Fan ST, Nimura Y, Figueras J, Capussotti L, Buchler MW, Weitz J (2011) Posthepatectomy liver failure: a definition and grading by the International Study Group of Liver Surgery (ISGLS). Surgery 149(5):713-724. https://doi.org/ 10.1016/j.surg.2010.10.001

4. Loss M, Jung EM, Scherer MN, Farkas SA, Schlitt HJ (2010) Surgical treatment of liver metastases. Chirurg 81(6):533-541. https://doi.org/10.1007/s00104-010-1891-9

5. Tanaka K, Shimada H, Matsuo K, Ueda M, Endo I, Togo S (2007) Remnant liver regeneration after two-stage hepatectomy for multiple bilobar colorectal metastases. Eur J Surg Oncol 33(3):329-335. https://doi.org/10.1016/j.ejso.2006.10.038

6. Tanaka K, Shimada H, Matsuo K, Ueda M, Endo I, Togo S (2007) Regeneration after two-stage hepatectomy vs. repeat resection for colorectal metastasis recurrence. J Gastrointest Surg 11(9):11541161. https://doi.org/10.1007/s11605-007-0221-0

7. Tucker ON, Heaton N (2005) The 'small for size' liver syndrome. Curr Opin Crit Care 11(2):150-155

8. Schnitzbauer AA, Lang SA, Goessmann H, Nadalin S, Baumgart J, Farkas SA, Fichtner-Feigl S, Lorf T, Goralcyk A, Horbelt R, Kroemer A, Loss M, Rummele P, Scherer MN, Padberg W, Konigsrainer A, Lang H, Obed A, Schlitt HJ (2012) Right portal vein ligation combined with in situ splitting induces rapid left lateral liver lobe hypertrophy enabling 2-staged extended right hepatic resection in small-for-size settings. Annals of surgery 255(3):405414. https://doi.org/10.1097/SLA.0b013e31824856f5

9. Schadde E, Ardiles V, Robles-Campos R, Malago M, Machado M, Hernandez-Alejandro R, Soubrane O, Schnitzbauer AA, Raptis D, Tschuor C, Petrowsky H, De Santibanes E, Clavien PA, Group AR (2014) Early survival and safety of ALPPS: first report of the International ALPPS Registry. Annals of surgery 260(5):829836; discussion 836-828. https://doi.org/10.1097/SLA. 0000000000000947

10. Edmondson MJ, Sodergren MH, Pucher PH, Darzi A, Li J, Petrowsky H, Campos RR, Serrablo A, Jiao LR (2016) Variations and adaptations of associated liver partition and portal vein ligation for staged hepatectomy (ALPPS): many routes to the summit. Surgery 159(4):1058-1072. https://doi.org/10.1016/j.surg. 2015.11.013

11. Lang H, Baumgart J, Mittler J (2018) Associating liver partition and portal vein ligation for staged hepatectomy in the treatment of colorectal liver metastases: current scenario. Dig Surg 35(4):294-302. https://doi.org/10.1159/000488097

12. Lau WY, Lai EC, Lau SH (2017) Associating liver partition and portal vein ligation for staged hepatectomy: the current role and development. Hepatobiliary Pancreat Dis Int 16(1):17-26. https:// doi.org/10.1016/s1499-3872(16)60174-1

13. Guiu B, Chevallier P, Denys A, Delhom E, Pierredon-Foulongne MA, Rouanet P, Fabre JM, Quenet F, Herrero A, Panaro F, Baudin G, Ramos J (2016) Simultaneous trans-hepatic portal and hepatic vein embolization before major hepatectomy: the liver venous deprivation technique. Eur Radiol 26(12):4259-4267. https://doi.org/ 10.1007/s00330-016-4291-9

14. Guiu B, Quenet F, Escal L, Bibeau F, Piron L, Rouanet P, Fabre JM, Jacquet E, Denys A, Kotzki PO, Verzilli D, Deshayes E (2017) Extended liver venous deprivation before major hepatectomy induces marked and very rapid increase in future liver remnant function. Eur Radiol 27(8):3343-3352. https://doi.org/10.1007/s00330017-4744-9

15. Panaro F, Giannone F, Riviere B, Sgarbura O, Cusumano C, Deshayes E, Navarro F, Guiu B, Quenet F (2019) Perioperative impact of liver venous deprivation compared with portal venous embolization in patients undergoing right hepatectomy: preliminary results from the pioneer center. Hepatobiliary Surg Nutr 8(4):329 337. https://doi.org/10.21037/hbsn.2019.07.06

16. Schadde E, Guiu B, Deal R, Kalil J, Arslan B, Tasse J, Olthof PB, Heil J, Schnitzbauer AA, Jakate S, Breitenstein S, Schlapfer M, Beck Schimmer B, Hertl M (2019) Simultaneous hepatic and portal vein ligation induces rapid liver hypertrophy: a study in pigs. Surgery 165(3):525-533. https://doi.org/10.1016/j.surg.2018.09. 001

17. Desmet VJ, Gerber M, Hoofnagle JH, Manns M, Scheuer PJ (1994) Classification of chronic hepatitis: diagnosis, grading and staging. Hepatology 19(6):1513-1520

18. Scheuer PJ (1991) Classification of chronic viral hepatitis: a need for reassessment. J Hepatol 13(3):372-374. https://doi.org/10.1016/ 0168-8278(91)90084-0

19. Mullen JT, Ribero D, Reddy SK, Donadon M, Zorzi D, Gautam S, Abdalla EK, Curley SA, Capussotti L, Clary BM, Vauthey JN (2007) Hepatic insufficiency and mortality in 1,059 noncirrhotic patients undergoing major hepatectomy. J Am Coll Surg 204(5): 854-862; discussion 862-854. https://doi.org/10.1016/j. jamcollsurg.2006.12.032

20. Schlitt HJ, Hackl C, Lang SA (2017) 'In-situ split' liver resection/ ALPPS - historical development and current practice. Visc Med 33(6):408-412. https://doi.org/10.1159/000479850

21. Heil J, Schadde E (2020) Simultaneous portal and hepatic vein embolization before major liver resection. Langenbeck's Arch Surg. https://doi.org/10.1007/s00423-020-01960-6 
22. Torres OJ, Moraes-Junior JM, Lima e Lima NC, Moraes AM (2012) Associating liver partition and portal vein ligation for staged hepatectomy (ALPPS): a new approach in liver resections. Arq Bras Cir Dig 25(4):290-292. https://doi.org/10.1590/s010267202012000400015

23. Hwang S, Lee SG, Ko GY, Kim BS, Sung KB, Kim MH, Lee SK, Hong HN (2009) Sequential preoperative ipsilateral hepatic vein embolization after portal vein embolization to induce further liver regeneration in patients with hepatobiliary malignancy. Annals of surgery 249(4):608-616. https://doi.org/10.1097/SLA. $0 \mathrm{~b} 013 \mathrm{e} 31819 \mathrm{ecc} 5 \mathrm{c}$

24. Nadalin S, Capobianco I, Li J, Girotti P, Konigsrainer I, Konigsrainer A (2014) Indications and limits for associating liver partition and portal vein ligation for staged hepatectomy (ALPPS). Lessons learned from 15 cases at a single centre. Z Gastroenterol 52(1):35-42. https://doi.org/10.1055/s-0033-1356364

25. Lang H, de Santibanes E, Schlitt HJ, Malago M, van Gulik T, Machado MA, Jovine E, Heinrich S, Ettorre GM, Chan A, Hernandez-Alejandro R, Robles Campos R, Sandstrom P, Linecker M, Clavien PA (2019) 10th anniversary of ALPPSlessons learned and quo vadis. Annals of surgery 269(1):114119. https://doi.org/10.1097/SLA.0000000000002797

26. Chan KS, Low JK, Shelat VG (2020) Associated liver partition and portal vein ligation for staged hepatectomy: a review. Transl Gastroenterol Hepatol 5:37. https://doi.org/10.21037/tgh.2019.12. 01

27. Le Roy B, Dupre A, Gallon A, Chabrot P, Gagniere J, Buc E (2018) Liver hypertrophy: underlying mechanisms and promoting procedures before major hepatectomy. J Visc Surg 155(5):393-401. https://doi.org/10.1016/j.jviscsurg.2018.03.005

28. Jiao LR, Fajardo Puerta AB, Gall TMH, Sodergren MH, Frampton AE, Pencavel T, Nagendran M, Habib NA, Darzi A, Pai M, Thomas R, Tait P (2019) Rapid induction of liver regeneration for major hepatectomy (REBIRTH): a randomized controlled trial of portal vein embolisation versus ALPPS assisted with radiofrequency. Cancers (Basel) 11(3). https://doi.org/10.3390/ cancers11030302

29. Baili E, Tsilimigras DI, Filippou D, Ioannidis A, Bakopoulos A, Machairas N, Papalampros A, Petrou A, Schizas D, Moris D (2019) Associating liver partition and portal vein ligation for staged hepatectomy in patients with primary liver malignancies: a systematic review of the literature. J BUON 24(4):1371-1381

30. Zhang GQ, Zhang ZW, Lau WY, Chen XP (2014) Associating liver partition and portal vein ligation for staged hepatectomy (ALPPS): a new strategy to increase resectability in liver surgery. Int J Surg 12(5):437-441. https://doi.org/10.1016/j.ijsu.2014.03.009

31. Sparrelid E, van Gulik TM (2019) Tumor progression in two-stage liver resections-is the shorter inter-stage period in associated liver partition and portal vein ligation for staged hepatectomy (ALPPS) of benefit to the patient? Hepatobiliary Surg Nutr 8(3):316-317. https://doi.org/10.21037/hbsn.2019.01.18

32. Xiang F, Hu ZM (2019) Chance and challenge of associating liver partition and portal vein ligation for staged hepatectomy. Hepatobiliary Pancreat Dis Int 18(3):214-222. https://doi.org/10. 1016/j.hbpd.2019.04.006

33. Uribe M, Uribe-Echevarria S, Mandiola C, Zapata MI, Riquelme F, Romanque P (2018) Insight on ALPPS - associating liver partition and portal vein ligation for staged hepatectomy - mechanisms: activation of mTOR pathway. HPB : the official journal of the International Hepato Pancreato Biliary Association 20(8):729738. https://doi.org/10.1016/j.hpb.2018.02.636

34. Lafaro K, Buettner S, Maqsood H, Wagner D, Bagante F, Spolverato G, Xu L, Kamel I, Pawlik TM (2015) Defining post hepatectomy liver insufficiency: where do we stand? J Gastrointest Surg 19(11):2079-2092. https://doi.org/10.1007/s11605-0152872-6

35. Vicente E, Quijano Y, Ielpo B, Duran H, Diaz E, Fabra I, Olivares S, Prestera A, Caruso R (2015) Is "small for size syndrome" a relatively new complication after the ALPPS procedure? Updates Surg 67(3):273-278. https://doi.org/10.1007/s13304-015-0300-9

36. Zhang L, Yang Z, Zhang S, Wang W, Zheng S (2020) Conventional two-stage hepatectomy or associating liver partitioning and portal vein ligation for staged hepatectomy for colorectal liver metastases? A systematic review and meta-analysis. Front Oncol 10:1391. https://doi.org/10.3389/fonc.2020.01391

Publisher's note Springer Nature remains neutral with regard to jurisdictional claims in published maps and institutional affiliations. 